\title{
Performance of body mass index and percentage of body fat in predicting cardiometabolic risk factors in Thai adults
}

This article was published in the following Dove Press journal: Diabetes, Metabolic Syndrome and Obesity:Targets and Therapy

\author{
Somlak Vanavanan' \\ Pornpen Srisawasdi' \\ Mana Rochanawutanon ${ }^{2}$ \\ Nalinee Kumproa' \\ Khanat Kruthkul ${ }^{3}$ \\ Martin $\mathrm{H} \mathrm{Kroll}{ }^{4}$ \\ 'Division of Clinical Chemistry, \\ Department of Pathology, Faculty \\ of Medicine, Ramathibodi Hospital, \\ Mahidol University, Bangkok, Thailand; \\ ${ }^{2}$ National Healthcare Systems, \\ Bangkok, Thailand; ${ }^{3}$ Department \\ of Medicine, Faculty of Medicine, \\ Ramathibodi Hospital, Mahidol \\ University, Bangkok, Thailand; ${ }^{4}$ Quest \\ Diagnostics, Madison, NJ, USA
}

Background: Body mass index (BMI) and percentage of body fat (PBF) are used to measure obesity; however, their performance in identifying cardiometabolic risk in Southeast Asians is unclear. Generally, Asian women have higher PBF and lower BMI than do men and other ethnic populations. This study was conducted to address whether a discord exists between these measures in predicting obesity-related cardiometabolic risk in a Thai population and to test whether associations between the measures and risk factors for cardiovascular disease have a sex-specific inclination.

Methods: A total of 234 (76 men and 158 women) outpatients were recruited. BMI obesity cutoff points were $\geq 25.0$ and $\geq 27.0 \mathrm{~kg} / \mathrm{m}^{2}$ and PBF cutoff points were $\geq 35.0 \%$ and $\geq 25.0 \%$ for women and men, respectively. Blood samples were analyzed for total cholesterol, triglycerides, low-density lipoprotein-cholesterol, high-density lipoprotein-cholesterol, lipoprotein subclasses, apolipoprotein A-I, apolipoprotein B, glucose, hemoglobin A1c, insulin, high-sensitive C-reactive protein (hsCRP), adiponectin, leptin, and 25-hydroxyvitamin D.

Results: Twenty-five percent of participants classified as normal-BMI had excessive fat, whereas 9\% classified as normal-PBF had excessive BMI. Good relationships were found between $\mathrm{BMI}$ and PBF using sex stratification $\left(R^{2}>0.5\right)$. The prevalence of metabolic syndrome was markedly increased in overweight and/or excess body fat groups compared with lean group. Logistic regression analyses showed that BMI was the best predictor of hypertension. BMI was an independent predictor of insulin resistance, hyperglycemia, hypertriglyceridemia, and hyperleptinemia in women, whereas PBF was for men. However, PBF proved to be a good indicator for atherogenic lipoprotein particles in both sexes. Notably, neither index predicted increased hsCRP or 25-hydroxyvitamin D insufficiency.

Conclusion: Considerable sex-specific variations were observed between BMI and PBF in their associations with and predictability of numerous cardiometabolic biomarkers. No single measure provides a comprehensive risk predication as shown herein with the Thai population, and therefore both should be applied in screening activities.

Keywords: obesity, body mass index, percentage of body fat, Southeast Asian population, cardiometabolic risk biomarkers, obesity-related metabolic disorders

\section{Introduction}

The prevalence of obesity is increasing globally, and obesity is thus becoming a major public health concern. ${ }^{1,2}$ The global obesity prevalence is predicted to reach $18 \%$ in men and over $21 \%$ in women by $2025 .^{2}$ Obesity results from a lack of balance between calorie intake and energy expenditure, which increases adipose tissue and activates endocrine entities. ${ }^{3}$ Adipose tissue secretes adipokines, which influence many metabolic
Division of Clinical Chenistrisawasd Department of Pathology, Faculty of Medicine, Ramathibodi Hospital, Mahidol University, Rama VI Road, Ratchathewi, Bangkok 10400, Thailand

Tel +6622010008

Fax +66 23547266

Email srisawasdiP@yahoo.com 
functions (including appetite, satiety, energy expenditure, activity, insulin sensitivity and secretion, glucose and lipid metabolism, fat distribution, neuroendocrine regulation, and immune system function). Consequently, obesity plays a major role in causing cardiometabolic complications including hypertension, type II diabetes mellitus, dyslipidemia, and certain cancers. ${ }^{4}$

Although visceral fat mass and, in particular, liver fat content have been shown to be valuable in predicting cardiometabolic risk, conducting such measurements is limited by costs, availability of instruments, and the requirement of highly trained technicians. ${ }^{5}$ By contrast, the body mass index (BMI) is easy to use because it is calculated using body weight in kilograms divided by the square of an individual's height in meters $\left(\mathrm{kg} / \mathrm{m}^{2}\right)$. As such, it is the most commonly used measure of weight status in epidemiology, clinical care, and clinical nutrition. BMI represents weight adjusted for height and aims to represent fat mass, fat-free mass, and body fluid. Scientific evidence indicates that a high BMI is associated with being overweight and obese, and is a predictor for all-cause mortality. ${ }^{6,7}$ However, BMI does not address fat distribution or discriminate between lean mass and fat mass, and these need to be defined using different methods because they represent body adiposity. ${ }^{8}$ In this respect, the percentage of body fat (PBF) is an effective measure of adiposity because it has been shown to be associated with metabolic dysregulation, regardless of body weight. ${ }^{9}$ Large-scale studies have shown that BMI correlates highly with PBF and such correlation is stable with height. ${ }^{10,11}$ For example, a study conducted on a US adult population demonstrated a high relationship between $\mathrm{BMI}$ and $\mathrm{PBF}$, enabling the prediction of PBF based on BMI classification. ${ }^{11}$ In global clinical practice, both BMI and PBF are widely accepted as accurate measures of obesity. ${ }^{12}$

On the basis of general trends in the relationship between BMI and morbidity and mortality rates, the World Health Organization uses BMI cutoff points for classifying overweight and obesity in the global adult population that are greater than, or equal to, 25 and $30 \mathrm{~kg} / \mathrm{m}^{2}$, respectively. ${ }^{13}$ These cutoff points have been applied in research and clinical practice, regardless of age, sex, or race/ethnicity. ${ }^{14}$ However, considering a population-specific BMI cutoff in Asian populations is necessary because Asians have different contributions of bone mass, muscle mass, and fluid to body weight than European populations, resulting in a reduced association between BMI, PBF, and health risk. ${ }^{15}$ In addition, Asian populations have higher or lower PBF at a specific BMI than white or European populations, and this is dependent on cultural subgroups, social and economic conditions, and nutritional factors. ${ }^{15,16}$ For example, a recent study conducted with Asian-Americans showed that BMI did not accurately reflect underlying adiposity and thus showed poor sensitivity in detecting PBF, especially in women. ${ }^{17}$ Women have a higher PBF than men at all ages and in all ethnic groups. A relatively high PBF may put Asian-American women at risk of future obesity-related diseases. In Thai populations, Pongchaiyakul et al determined the optimal cutoff values of BMI for defining obesity in men and women. ${ }^{18}$ However, the PBF cutoff points do not agree with those of BMI with respect to given sex-specific obesity cutoff points. For example, the optimum BMI obesity cutoff point for women $\left(\geq 25.0 \mathrm{~kg} / \mathrm{m}^{2}\right)$ is actually lower than that for men $\left(\geq 27.0 \mathrm{~kg} / \mathrm{m}^{2}\right)$, whereas the corresponding PBF cutoff point is higher for women $(\geq 35 \%)$ than for men $(\geq 25 \%)$. Therefore, BMI and PBF values are not directly comparable.

Obesity causes chronic inflammatory diseases and mainly contributes to the development of insulin resistance, several components of metabolic syndrome (MetS), and systematic low-grade inflammation. As mentioned, BMI and PBF results associated with obesity-related risk factors are controversial with respect to differing racial/ethnicity populations, and less is known about the performance of these obesity measures in Southeast Asian countries, most of which are classified as "developing countries". ${ }^{14,19}$ Therefore, the aim of this study was to compare the performance of BMI and PBF in identifying major risk factors and new emerging risk factors for cardiovascular disease (CVD) in an adult Thai population. We also conducted the study to test whether associations between the measures and cardiometabolic risk factors have a sex-specific inclination. Information obtained in this study could be applied across Southeast Asian populations with similar ethnic and cultural subgroups, degrees of urbanization, and social and economic determinants of health and nutrition statuses.

\section{Materials and methods Study participants}

This cross-sectional study enrolled a total of 234 outpatients who were aged at least 20 years and were receiving wellness check-ups in the general clinic at Ramathibodi Hospital, a hospital associated with the Faculty of Medicine of Mahidol University in Bangkok, Thailand. Patient exclusion criteria included a prior history of CVD or taking lipid-lowering drugs, or having had cancer, end-stage chronic kidney disease, or another serious medical condition. Data were obtained using a questionnaire and physical examination. All participants provided written informed consent, and the study 
protocol was reviewed and approved by the Committee on Human Rights Related to Research Involving Human Subjects, Faculty of Medicine, Ramathibodi Hospital, Mahidol University (MURA2017/348). All methods were carried out in accordance with the Declaration of Helsinki.

Body composition analysis was conducted using a multifrequency bioelectrical impedance analyzer (Biospace ${ }^{\mathrm{TM}} \mathrm{InBody}$ 720 body composition analyzer; GE Healthcare, Chicago, IL, USA). Criteria for defining obesity in the adult Thai population were a BMI level of $\geq 25.0 \mathrm{~kg} / \mathrm{m}^{2}$ for women and $\geq 27.0 \mathrm{~kg} / \mathrm{m}^{2}$ for men, and a PBF level of $\geq 35 \%$ for women and $\geq 25 \%$ for men. ${ }^{18}$ Participants with BMI measurements below or above mentioned cutoff points were defined as being of a normal weight or overweight, respectively. Participants with PBF measurements below or above mentioned cutoff points were defined as lean or fat, respectively. MetS was defined using National Cholesterol Education Program-Third Adult Treatment Panel (NCEP ATP III) criteria modified for Asian populations. ${ }^{20}$

\section{Biochemical measurements}

Blood samples were collected during a fasting state. All samples were analyzed for total cholesterol, triglycerides, low density lipoprotein-cholesterol (LDL-C), high density lipoprotein-cholesterol (HDL-C), glucose, apolipoprotein (apo) A-I (apoA-I), apoB, lipoprotein subclass, high-sensitive C-reactive protein (hsCRP), insulin, adiponectin, leptin, 25-hydroxyvitamin D, and hemoglobin A1c (HbAlc). Lipid profiles and glucose were measured using enzymatic methods (Siemens Medical Solution Diagnostics, Tarrytown, NY, USA). ApoA-I, apoB, and hsCRP were measured using a Siemens BN ProSpec, and adiponectin and leptin levels were quantified using the ELISA system (Mediagnost Gesellschaft für Forschung und Herstellung von Diagnostika GmbH, Kusterdigen, Germany). HbA1c was determined using the Cobas Integra immunoturbidimetric method (Roche Diagnostics Ltd., Rotkreuz, Switzerland), and insulin and 25-hydroxyvitamin D levels were determined using the Immulite H2975 (Siemens Medical Solution Diagnostics) and LIAISON ${ }^{\circledR}$ Analyzer (DiaSorin, Stillwater, MN, USA), respectively. Insulin resistance was estimated using the Homeostasis Model Assessment of Insulin Resistance (HOMA-IR), the index for which was calculated according to the following formula: HOMA-IR = fasting insulin $(\mu \mathrm{IU} /$ $\mathrm{mL}) \times$ fasting glucose $(\mathrm{mmol} / \mathrm{L}) / 22.5$.

Lipoprotein subclass was analyzed using polyacrylamide tube gel electrophoresis (Lipoprint ${ }^{\mathrm{TM}}$; Quantimetrix, Redondo Beach, CA, USA), which electrophoretically separates plasma lipoproteins into the following bands: very low density (VLDL); intermediate low density (IDL): midband-C (MIDC),
midband-B (MIDB) and midband-A (MIDA); large-buoyant LDL (LDL1 and LDL2); small-dense LDL (LDL3-LDL7); and HDL. Relative areas for each lipoprotein band were determined by densitometry and multiplied by total cholesterol concentration to yield the amount of cholesterol for each band. Mean LDL particle sizes were computed. The atherogenic lipoprotein pattern was defined by a small-dense LDL of $>0.16$ $\mathrm{mmol} / \mathrm{L}$ or a mean LDL particle size of $<26.5 \mathrm{~nm}$.

\section{Statistical analyses}

Data are expressed as mean values (standard error of mean), and categorical variables are presented as numbers and percentages. Data were compared using the $\chi^{2}$ test, Student's $t$-test, Mann-Whitney $U$ test, or ANOVA, as appropriate. The correlation between BMI and PBF was analyzed using Pearson's correlation test. All participants were stratified into four groups based on BMI and PBF cutoff points: normal weight and lean (Group A), BMI $<25.0 \mathrm{~kg} / \mathrm{m}^{2}$ for women and $<27.0$ $\mathrm{kg} / \mathrm{m}^{2}$ for men, and $\mathrm{PBF}<35 \%$ for women and $<25 \%$ for men; overweight and lean (Group B), BMI $\geq 25.0 \mathrm{~kg} / \mathrm{m}^{2}$ for women and $\geq 27.0 \mathrm{~kg} / \mathrm{m}^{2}$ for men, and $\mathrm{PBF}<35 \%$ for women and $<25 \%$ for men; normal weight and fat (Group C), BMI $<25.0 \mathrm{~kg} / \mathrm{m}^{2}$ for women and $<27.0 \mathrm{~kg} / \mathrm{m}^{2}$ for men, and PBF $\geq 35 \%$ for women and $\geq 25 \%$ for men; and overweight and fat (Group D), BMI $\geq 25.0 \mathrm{~kg} / \mathrm{m}^{2}$ for women and $\geq 27.0 \mathrm{~kg} / \mathrm{m}^{2}$ for men, and $\mathrm{PBF} \geq 35 \%$ for women and $\geq 25 \%$ for men. To conduct a risk analysis among patient groups, the odds ratios (ORs) and 95\% confidence intervals (CIs) of cardiometabolic risk factors (classified as dichotomous variables) in Groups B, C, and D were compared with those in Group A (used as a reference) and analyzed using the multinomial logistic regression model adjusted for sex, age group (divided into four groups: $<40,40-<50,50-<60, \geq 60$ years), and smoking status. A backward, stepwise multivariable logistic regression model adjusted for age, height, and smoking status was used to determine the association of each cardiometabolic risk (set as a dependent variable) with BMI and PBF (set as independent variables). Sex stratification was used in the analysis. Outcomes were considered statistically significant when $P$-values were $<0.05$, and all analyses were performed using SPSS version 18 (SPSS Inc., Chicago, IL, USA).

\section{Results Characteristics and biomarkers of study population}

Table 1 presents a summary of the demographic characteristics and biochemical test results for all participants (76 men 
Table I Characteristics of participants defined as nonobese and obese using obesity measures

\begin{tabular}{|c|c|c|c|c|c|c|}
\hline \multirow[t]{2}{*}{ Variables } & \multicolumn{3}{|l|}{ Body mass index } & \multicolumn{3}{|c|}{ Percentage of body fat } \\
\hline & $\begin{array}{l}\text { Normal weight } \\
(N=169)\end{array}$ & $\begin{array}{l}\text { Overweight } \\
(\mathrm{N}=65)\end{array}$ & $P$-value & $\begin{array}{l}\text { Lean } \\
(N=139)\end{array}$ & $\begin{array}{l}\text { Fat } \\
(N=95)\end{array}$ & $P$-value \\
\hline Male, n (\%) & $56(33.1)$ & $20(30.8)$ & 0.758 & $46(33.1)$ & $30(31.6)$ & 0.808 \\
\hline Age, years & $5 \mathrm{I} .4(\mathrm{I} . \mathrm{I})$ & $52.7(1.4)$ & 0.509 & $49.4(1.2)$ & $55.3(I . I)$ & 0.001 \\
\hline Body mass, $\mathrm{kg}$ & $56.8(0.6)$ & $71.6(1.4)$ & $<0.001$ & $56.9(0.8)$ & $66.8(1.2)$ & $<0.001$ \\
\hline Height (cm) & $160.4(0.6)$ & I58.7 (I.0) & 0.145 & $160.9(0.7)$ & I $58.5(0.8)$ & 0.026 \\
\hline Waist circumference, $\mathrm{cm}$ & $80.5(0.8)$ & $93.6(1.1)$ & $<0.001$ & $79.7(1.0)$ & $90.7(0.9)$ & $<0.001$ \\
\hline Body mass index, $\mathrm{kg} / \mathrm{m}^{2}$ & $22.00(0.16)$ & $28.32(0.38)$ & $<0.001$ & $21.88(0.21)$ & $26.50(0.37)$ & $<0.001$ \\
\hline Lean body mass, $\mathrm{kg}$ & $22.3 I(0.4 I)$ & $24.77(0.80)$ & 0.002 & $23.19(0.50)$ & $22.70(0.58)$ & 0.517 \\
\hline Body fat mass, $\mathrm{kg}$ & $15.80(0.35)$ & $26.34(0.79)$ & $<0.001$ & $14.49(0.33)$ & $24.87(0.59)$ & $<0.001$ \\
\hline Body fat mass, \% & $27.95(0.59)$ & $37.11(0.95)$ & $<0.001$ & $25.72(0.56)$ & $37.43(0.65)$ & $<0.001$ \\
\hline Waist-hip fat ratio & $0.890(0.004)$ & $0.945(0.007)$ & $<0.001$ & $0.879(0.004)$ & $0.945(0.005)$ & $<0.001$ \\
\hline Visceral fat area, $\mathrm{cm}^{2}$ & $86.6(2.0)$ & $123.8(3.5)$ & $<0.001$ & $79.7(2.0)$ & $122.0(2.5)$ & $<0.001$ \\
\hline \multicolumn{7}{|l|}{ Biochemical measures } \\
\hline Insulin, $\mu \mathrm{IU} / \mathrm{mL}$ & $3.98(0.32)$ & $6.85(0.68)$ & $<0.001$ & $3.64(0.33)$ & $6.45(0.55)$ & $<0.001$ \\
\hline HOMA-IR & $0.972(0.083)$ & $1.935(0.264)$ & $<0.001$ & $0.895(0.100)$ & $1.743(0.188)$ & $<0.001$ \\
\hline Glucose, $\mathrm{mmol} / \mathrm{L}$ & $5.34(0.08)$ & $5.84(0.20)$ & 0.004 & $5.27(0.08)$ & $5.80(0.15)$ & 0.001 \\
\hline $\mathrm{HbAlc}, \mathrm{mmol} / \mathrm{mol}$ & $42.4(0.7)$ & $45.2(1.1)$ & 0.038 & $41.7(0.8)$ & $45.3(0.9)$ & 0.003 \\
\hline Triglycerides, mmol/L & $1.20(0.04)$ & $1.66(0.10)$ & $<0.001$ & $1.15(0.05)$ & $1.58(0.08)$ & $<0.001$ \\
\hline Total cholesterol, $\mathrm{mmol} / \mathrm{L}$ & $5.67(0.08)$ & $5.65(0.13)$ & 0.865 & $5.66(0.08)$ & $5.68(0.11)$ & 0.875 \\
\hline $\mathrm{HDL}-\mathrm{C}, \mathrm{mmol} / \mathrm{L}$ & $1.47(0.03)$ & $1.29(0.04)$ & $<0.001$ & $1.49(0.03)$ & $1.32(0.03)$ & $<0.001$ \\
\hline LDL-C, mmol/L & $3.44(0.06)$ & $3.5 I(0.10)$ & 0.593 & $3.42(0.07)$ & $3.53(0.09)$ & 0.344 \\
\hline \multicolumn{7}{|l|}{ Lipoprotein subclass, $\mathrm{mmo} / \mathrm{L}$} \\
\hline VLDL & $0.88(0.02)$ & $0.98(0.03)$ & 0.005 & $0.87(0.02)$ & $0.95(0.03)$ & 0.014 \\
\hline MIDC & $0.47(0.01)$ & $0.48(0.02)$ & 0.853 & $0.46(0.01)$ & $0.49(0.02)$ & 0.137 \\
\hline MIDB & $0.40(0.01)$ & $0.40(0.02)$ & 0.797 & $0.40(0.01)$ & $0.4 \mathrm{I}(0.0 \mathrm{I})$ & 0.677 \\
\hline MIDA & $0.55(0.02)$ & $0.5 \mathrm{I}(0.03)$ & 0.261 & $0.55(0.02)$ & $0.52(0.02)$ & 0.339 \\
\hline LDLI & $1.08(0.02)$ & $1.01(0.05)$ & 0.133 & $1.10(0.03)$ & $1.00(0.04)$ & 0.039 \\
\hline LDL2 & $0.69(0.02)$ & $0.72(0.03)$ & $0.44 I$ & $0.68(0.02)$ & $0.73(0.03)$ & 0.187 \\
\hline Small-dense LDL & $0.23(0.02)$ & $0.36(0.05)$ & 0.009 & $0.20(0.02)$ & $0.36(0.04)$ & $<0.001$ \\
\hline Mean LDL particle size, $\mathrm{nm}$ & $26.80(0.04)$ & $26.58(0.08)$ & 0.005 & $26.84(0.04)$ & $26.59(0.06)$ & $<0.001$ \\
\hline Non-HDL-C, mmol/L & $4.19(0.08)$ & $4.34(0.12)$ & 0.308 & $4.16(0.08)$ & $4.34(0.11)$ & 0.173 \\
\hline ApoA-l, mg/dL & $160.2(1.9)$ & $152.3(3.2)$ & 0.034 & $161.6(2.1)$ & $152.7(2.6)$ & 0.009 \\
\hline ApoB, mg/dL & $97.8(1.7)$ & $103.8(2.7)$ & 0.058 & $96.4(1.7)$ & $104.0(2.4)$ & 0.009 \\
\hline hsCRP, mg/L & I.8II (0.352) & $3.670(0.837)$ & 0.016 & $1.315(0.177)$ & $3.809(0.795)$ & $<0.001$ \\
\hline 25-hydroxyvitamin $\mathrm{D}, \mathrm{nmol} / \mathrm{L}$ & $53.0(1.5)$ & $49.6(2.0)$ & 0.208 & $53.0(1.8)$ & $50.6(1.5)$ & 0.310 \\
\hline Leptin, ng/mL & $8.04(0.45)$ & $16.66(1.36)$ & $<0.001$ & $7.19(0.47)$ & $15.26(1.00)$ & $<0.001$ \\
\hline Adiponectin, $\mathrm{mg} / \mathrm{mL}$ & $23.00(1.29)$ & $17.06(1.30)$ & 0.009 & $23.45(1.48)$ & $18.21(1.16)$ & 0.012 \\
\hline
\end{tabular}

Notes: Data except for number (\%) are the mean (standard error of mean). All biochemical markers are expressed in Système International units; conversions to conventional units are as follows: fasting glucose (mg/dL), multiply by 18.02 ; HbAlc (\%), use the formula: [0.09/5 HbAlc (mmol/mol) + 2.l5]; triglycerides (mg/dL), multiply by 88.5 ; cholesterol $(\mathrm{mg} / \mathrm{dL})$, multiply by $38.6 ; 25$-hydroxyvitamin $\mathrm{D}(\mathrm{ng} / \mathrm{mL})$, multiply by 0.40 .

Abbreviations: ApoA-I, apolipoprotein A-I; ApoB, apolipoprotein B; HbAlc, hemoglobin AIc; HDL, high density lipoprotein; HDL-C, high density lipoprotein-cholesterol; HOMA-IR, Homeostasis Model Assessment of Insulin Resistance; hsCRP, high sensitive C-reactive protein; LDL, low density lipoprotein; LDL-C, low density lipoproteincholesterol; MID, intermediate density lipoprotein midband; VLDL, very low density lipoprotein.

and 158 women) who had a mean age of 51.8 years (minmax: 21-79 years) and were classified as obese or nonobese using BMI or PBF cutoff points. More participants exceeded the PBF cutoff for fat (40.6\%) than for BMI-based overweight (27.8\%). Participants classified as either overweight or fat had a significantly higher body fat mass, waist-hip fat ratio, and visceral fat area than those classified as normal weight or lean. A wide range of PBF $(7.3 \%-50.7 \%)$ was observed among normal-weight participants. Similarly, a wide range of BMI (16.9-29.5 kg/m²) was observed among lean participants. The results obtained for metabolic biomarkers were similar for the normal-weight and overweight groups and the lean and fat groups, with the exception of LDL1 and apoB, which showed significant differences between the lean and fat groups. The following were noted in participants who were considered overweight or fat compared with the normalweight or lean group: higher levels of glucose homeostasis markers (insulin, HOMA-IR, fasting glucose, and HbA1c), 
triglycerides, VLDL, small-dense LDL, apoB, leptin, and hsCRP, but lower levels of HDL-C, ApoA-I, and adiponectin concentrations and mean LDL particle sizes. However, the results revealed no significant differences in mean concentrations of total cholesterol, LDL-C, IDL-C (MIDC to MIDA), non-HDL-C, and 25-hydroxyvitamin D between the normalweight and overweight or lean and fat groups.

\section{Correlation between $\mathrm{BMI}$ and PBF}

The correlation between BMI and PBF for all participants is shown in Figure 1A. Linear regression statistics revealed a moderate relationship between BMI (x) and PBF (y): $\mathrm{y}=$ $1.25 \times+0.82, R^{2}=0.287$. A superior relationship was found with respect to sex stratification, where linear regression statistics were $\mathrm{y}=1.51 \times-13.20, R^{2}=0.556$ for men (Figure 1B) and $\mathrm{y}=1.44 \mathrm{x}+0.05, R^{2}=0.522$ for women (Figure 1C).

\section{Characteristics and biomarkers of groups based on different obesity measures}

Participants were categorized into four groups based on whether they exceeded BMI or PBF cutoff points. The proportions of men did not differ among all groups (Table 2). Of participants classified as normal weight, $25 \%$ had higher than cutoff values for PBF, whereas $9 \%$ of those classified as lean had a BMI that was higher than the cutoff value. For body composition, significant differences were observed between parameter values for all four groups, particularly with respect to the waist-to-hip fat ratios and visceral fat areas, which were clearly elevated in the participants with normal weight and fat and overweight and fat. A marked difference was found between the groups with respect to risk for individual components of MetS. Abdominal obesity, hypertension, hypertriglyceridemia, and hyperglycemia were more highly prevalent in the subjects with overweight and fat, but those with overweight and lean had the highest prevalence of low HDL-C. The results indicated a marked increase in the prevalence of MetS (more than 50\%) in the groups of overweight and/or fat compared with normal weight and lean group.

Statistically significant differences were observed among the groups for most of the monitored variables, including glucose homeostatic biomarkers (insulin, HOMA-IR, glucose, and HbA1c), lipid biomarkers (VLDL, small-dense LDL, LDL particle size, triglycerides, HDL-C, and apoA-I), hsCRP, leptin, and adiponectin, as shown in Table 3. However, no significant differences in the levels of apoB and 25-hydroxyvitamin D were observed between the groups.
To compare the risk of cardiometabolic risk factors in the groups of overweight and/or fat with that of normal weight and lean, a multinomial logistic regression model was applied (Figure 2). The ORs (95\% CIs) for hypertension (Figure 2A) were significant in Group B, overweight and lean (7.28 [1.86-28.56]), and Group D, overweight and fat, (5.61 [2.51-12.54]) but they were not significant in Group C, normal weight and fat (2.05 [0.88-4.80]). Insulin resistance (Figure 2B) was statistically significant in normal weight and fat and overweight and fat groups: ORs (95\% CIs) were 2.43 (1.01-5.84) and 6.39 (2.97-13.77), respectively. However, impaired fasting glucose was only statistically significant in overweight and fat group (3.36 [1.59-7.11]) (Figure 2C). By contrast, there were no significant differences in the increased risk of $\mathrm{HbAlc}$ (Figure 2D) between all groups. For the lipid metabolic profile, the participants with overweight and/or fat showed a significantly high risk of hypertriglyceridemia (Figure 2E), with the corresponding ORs (95\% CI) being 5.33 (1.40-20.29), 2.80 (1.19-6.60), and 4.49 (2.03-9.92), respectively. Similarly, these participants showed a significant risk of low HDL-C (Figure 2F); however, large ORs were observed in overweight and lean group (6.71 [1.81-24.86]) and overweight and fat group (4.23 [1.90-9.44]). For the atherogenic lipoprotein pattern, the participants with overweight showed statistically significant ORs for increasing small-dense LDL (Figure 2G) and decreasing mean LDL particle size (Figure $2 \mathrm{H}$ ).

\section{Association between $\mathrm{BMI}$ and PBF and cardiometabolic risk factors stratified by sex}

A backward, stepwise removal process was applied to remove cardiometabolic risk factors exhibiting no significant $(P>0.05)$ association with BMI or PBF, and the remaining variables adjusted for age, height, and smoking status for analysis are shown in Table 4. BMI was associated with hypertension for both sexes. HOMA-IR and fasting glucose were associated with PBF for men, but were associated with BMI for women. HbAlc, hsCRP, and 25-hydroxyvitamin D were not associated with any measure for either sex. Differences were observed with respect to an association between the measures and lipid metabolic biomarkers. Similar to fasting glucose and HOMA-IR, triglycerides were associated with PBF for men but with BMI for women. HDL-C was related to BMI for both sexes, but atherogenic lipoprotein patterns (including small-dense LDL and mean LDL particle size) were related to PBF for both sexes. For adipokines, 

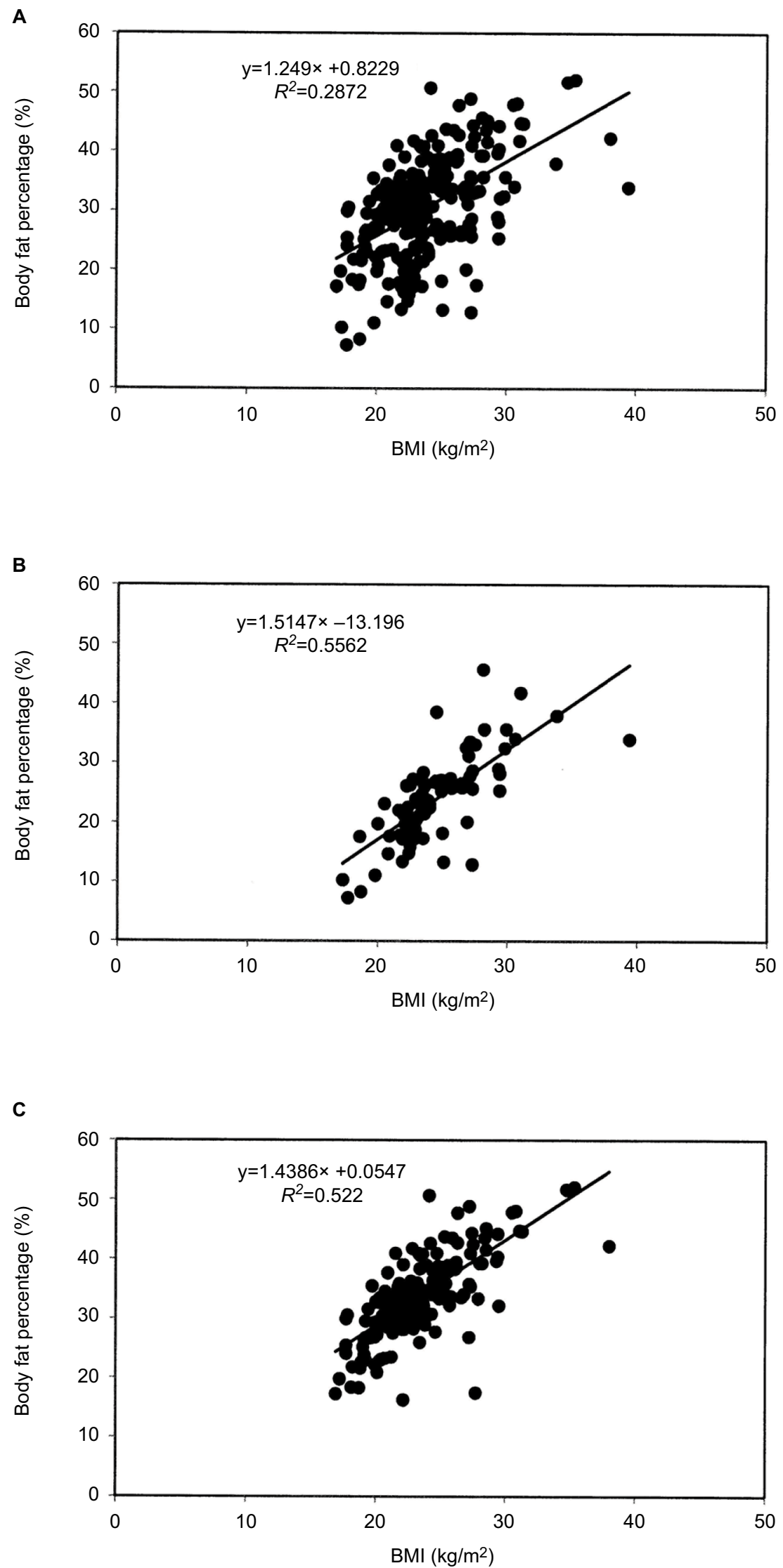

Figure I Correlation plots of body mass index (BMI) versus percentage of body fat (PBF) in (A) all participants; (B) men; and (C) women. 
Table 2 Characteristics of participants by group, as classified by BMI and PBF

\begin{tabular}{|c|c|c|c|c|c|}
\hline \multirow[t]{2}{*}{ Variables $^{a}$} & \multicolumn{4}{|c|}{ Categories of obesity indices ${ }^{b}$} & \multirow[t]{2}{*}{$P$-value } \\
\hline & $\begin{array}{l}\text { Group A } \\
(N=126)\end{array}$ & $\begin{array}{l}\text { Group B } \\
(N=13)\end{array}$ & $\begin{array}{l}\text { Group C } \\
(N=43)\end{array}$ & $\begin{array}{l}\text { Group D } \\
(N=52)\end{array}$ & \\
\hline Male, n (\%) & $42(33.3)$ & $4(30.8)$ & $14(32.6)$ & $16(30.8)$ & 0.995 \\
\hline Age, years & $49.4(1.3)$ & $49.3(3.2)$ & $57.3(\mathrm{I} .5)$ & $53.6(1.6)$ & 0.005 \\
\hline Smoke, n (\%) & $16(12.8)$ & $3(23.1)$ & $7(16.7)$ & $7(13.5)$ & 0.736 \\
\hline Height, cm & $160.7(0.7)$ & $163.1(2.2)$ & $159.6(1.2)$ & $157.6(1.1)$ & 0.058 \\
\hline Body mass index, $\mathrm{kg} / \mathrm{m}^{2}$ & $21.34(0.17)$ & $27.21(0.36)$ & $23.96(0.19)$ & $28.60(0.45)$ & $<0.001$ \\
\hline \multicolumn{6}{|l|}{ Bioelectrical impedance analysis } \\
\hline Lean body mass, $\mathrm{kg}$ & $22.55(0.48)$ & $29.47(1.87)$ & $21.6 \mathrm{I}(0.79)$ & $23.59(0.82)$ & $<0.001$ \\
\hline Body fat mass, $\mathrm{kg}$ & $13.93(0.31)$ & $19.88(1.17)$ & $21.14(0.4 I)$ & $27.96(0.80)$ & $<0.001$ \\
\hline Body fat mass, $\%$ & $25.49(0.58)$ & $27.92(2.01)$ & $35.04(0.93)$ & $39.40(0.82)$ & $<0.001$ \\
\hline Waist-hip fat ratio & $0.876(0.004)$ & $0.902(0.018)$ & $0.932(0.005)$ & $0.955(0.007)$ & $<0.001$ \\
\hline Visceral fat area, $\mathrm{cm}^{2}$ & $77.86(2.02)$ & $97.00(5.80)$ & III.7I (2.60) & $130.99(3.60)$ & $<0.001$ \\
\hline Abdominal obesity, $n(\%)^{c}$ & $35(27.8)$ & $12(92.3)$ & $33(75.0)$ & $50(98.0)$ & $<0.001$ \\
\hline Hypertension, n (\%) ${ }^{d}$ & $22(17.5)$ & $6(46.2)$ & $15(34.9)$ & $27(51.9)$ & $<0.001$ \\
\hline Triglycerides $\geq 1.70 \mathrm{mmol} / \mathrm{L}, \mathrm{n}(\%)$ & $18(14.3)$ & $5(38.5)$ & $16(37.2)$ & $22(42.3)$ & $<0.001$ \\
\hline $\begin{array}{l}\mathrm{HDL}-\mathrm{C}<\mathrm{I} .04 \mathrm{mmol} / \mathrm{L} \text { (men) or } \\
<1.30 \mathrm{mmol} / \mathrm{L} \text { (women), } \mathrm{n}(\%)\end{array}$ & $17(13.5)$ & $6(46.2)$ & $14(32.6)$ & $20(38.5)$ & $<0.001$ \\
\hline Hyperglycemia, $n(\%)^{\mathrm{e}}$ & $29(23.0)$ & $5(38.5)$ & $16(37.2)$ & $27(51.9)$ & 0.002 \\
\hline Metabolic syndrome, $\mathrm{n}(\%)^{f}$ & $18(14.3)$ & $7(53.8)$ & $22(5 \mid .2)$ & $34(65.4)$ & $<0.001$ \\
\hline
\end{tabular}

Notes: aData except for number (\%) are the mean (standard error of mean). 'lndividual group is defined as follows: Group A (normal-weight and lean), BMl $<25.0 \mathrm{~kg} / \mathrm{m}^{2}$ for women and $<27.0 \mathrm{~kg} / \mathrm{m}^{2}$ for men and $\mathrm{PBF}<35 \%$ for women and $<25 \%$ for men; Group B (overweight and lean), BMI $\geq 25.0 \mathrm{~kg} / \mathrm{m}^{2}$ for women and $\geq 27.0 \mathrm{~kg} / \mathrm{m}^{2}$ for men and PBF $<35 \%$ for women and $<25 \%$ for men; Group C (normal-weight and fat), BMl $<25.0 \mathrm{~kg} / \mathrm{m}^{2}$ for female and $<27.0 \mathrm{~kg} / \mathrm{m}^{2}$ for men and PBF $\geq 35 \%$ for women and $\geq 25 \%$ for men; and Group D (overweight and fat), BMI $\geq 25.0 \mathrm{~kg} / \mathrm{m}^{2}$ for women and $\geq 27.0 \mathrm{~kg} / \mathrm{m}^{2}$ for men and PBF $\geq 35 \%$ for women and $\geq 25 \%$ for men. ${ }^{\mathrm{c}} \mathrm{Defined}$ as waist circumference $\geq 90$ $\mathrm{cm}$ for men or $\geq 80 \mathrm{~cm}$ for women. ${ }^{\mathrm{d} D e f i n e d ~ a s ~ s y s t o l i c ~} \geq 130$ and/or diastolic $\geq 85 \mathrm{mmHg}$ or treatment with antihypertensive drug. ${ }^{e} D e f i n e d$ as fasting glucose $\geq 5.55 \mathrm{mmol} / \mathrm{L}$ or previous diagnosis of diabetes. 'Metabolic syndrome is defined using the NCEP ATP III criteria modified for Asian population. ${ }^{20}$

Abbreviations: BMI, body mass index; PBF, percentage of body fat; HDL-C, high density lipoprotein-cholesterol; NCEP ATP III, National Cholesterol Education ProgramThird Adult Treatment Panel.

Table 3 Comparison of metabolic biomarkers between groups defined using different obesity measures

\begin{tabular}{|c|c|c|c|c|c|}
\hline \multirow[t]{3}{*}{ Variables $^{\mathrm{a}}$} & \multicolumn{4}{|c|}{ Categories of obesity indices $^{b}$} & \multirow[t]{3}{*}{$P$-value } \\
\hline & Group A & Group B & Group C & Group D & \\
\hline & $\mathbf{N}=126$ & $N=13$ & $N=43$ & $\mathbf{N}=\mathbf{5 2}$ & \\
\hline Insulin, $\mu \mathrm{IU} / \mathrm{mL}$ & $3.52(0.33)$ & $4.75(1.54)$ & $5.33(0.79)$ & $7.37(0.75)$ & $<0.001$ \\
\hline HOMA-IR & $0.850(0.087)$ & $1.330(0.578)$ & $1.328(0.195)$ & $2.087(0.297)$ & $<0.001$ \\
\hline Glucose, $\mathrm{mmol} / \mathrm{L}$ & $5.24(0.08)$ & $5.46(0.27)$ & $5.63(0.18)$ & $5.94(0.23)$ & 0.004 \\
\hline $\mathrm{HbAlc}, \mathrm{mmol} / \mathrm{mol}$ & $4 I .5(0.8)$ & $43.7(2.3)$ & $45.0(1.3)$ & $45.6(1.3)$ & 0.023 \\
\hline VLDL, $\mathrm{mmol} / \mathrm{L}$ & $0.87(0.02)$ & $0.98(0.08)$ & $0.92(0.04)$ & $0.97(0.04)$ & 0.020 \\
\hline Small-dense LDL, mmol/L & $0.20(0.02)$ & $0.28(0.07)$ & $0.34(0.062)$ & $0.38(0.06)$ & 0.003 \\
\hline Mean LDL particle size, $\mathrm{nm}$ & $26.86(0.04)$ & $26.68(0.13)$ & $26.62(0.09)$ & $26.55(0.09)$ & 0.002 \\
\hline Triglycerides, $\mathrm{mmol} / \mathrm{L}$ & I.II (0.05) & $1.58(0.20)$ & $1.45(0.10)$ & $1.68(0.14)$ & $<0.001$ \\
\hline HDL-C, mmol/L & I.5I (0.03) & $1.27(0.10)$ & $1.34(0.05)$ & $1.30(0.04)$ & $<0.001$ \\
\hline ApoA-l, mg/dL & $163.0(2.3)$ & $148.0(7.4)$ & $151.9(3.8)$ & I53.4 (3.5) & 0.011 \\
\hline ApoB, mg/dL & $96.1(1.9)$ & 99.5 (3.9) & $102.8(3.7)$ & $104.9(3.2)$ & 0.064 \\
\hline hsCRP, mg/L & $1.232(0.185)$ & $2.118(0.565)$ & 3.507 (1.249) & $4.058(1.032)$ & 0.004 \\
\hline 25-hydroxyvitamin $\mathrm{D}, \mathrm{nmol} / \mathrm{L}$ & $53.8(1.9)$ & $45.7(4.1)$ & $50.5(1.9)$ & $50.6(2.2)$ & 0.339 \\
\hline Leptin, ng/mL & $6.70(0.44)$ & $11.72(2.23)$ & $12.02(1.02)$ & $18.02(1.58)$ & $<0.001$ \\
\hline Adiponectin, $\mu g / \mathrm{mL}$ & 24.07 (I.59) & $17.75(3.73)$ & $19.79(1.98)$ & $16.87(1.33)$ & 0.026 \\
\hline
\end{tabular}

Notes: aData are given as mean (standard error of mean). Individual group is defined as in Table 2.

Abbreviations: ApoA-I, apolipoprotein A-I; ApoB, apolipoprotein B; hsCRP, high sensitive C-reactive protein; HbAIc, hemoglobin Alc; HOMA-IR, Homeostasis Model Assessment of Insulin Resistance; HDL-C, high density lipoprotein-cholesterol; hsCRP, high sensitive C-reactive protein; LDL, low density lipoprotein; VLDL, very low density lipoprotein. 
A

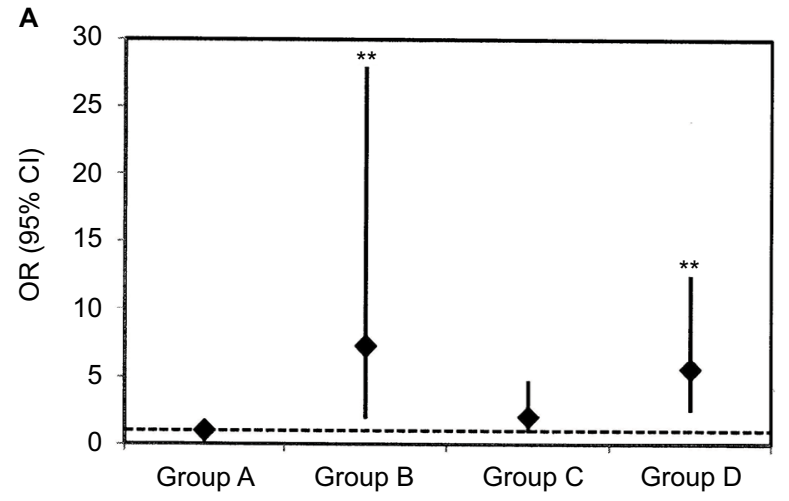

C

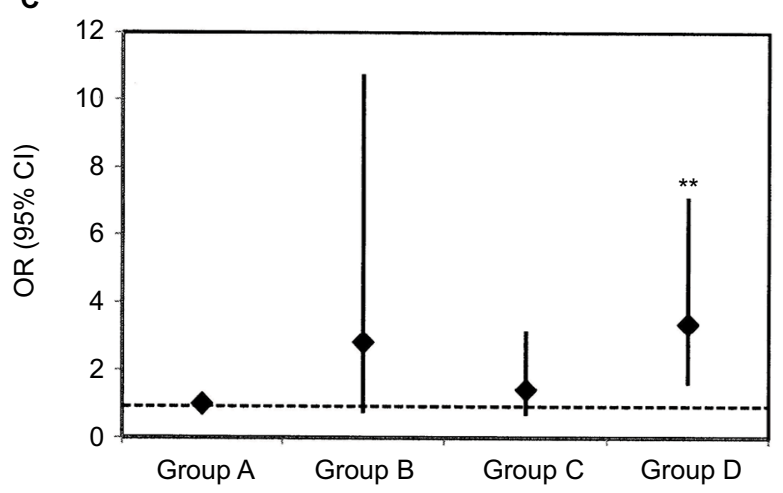

B

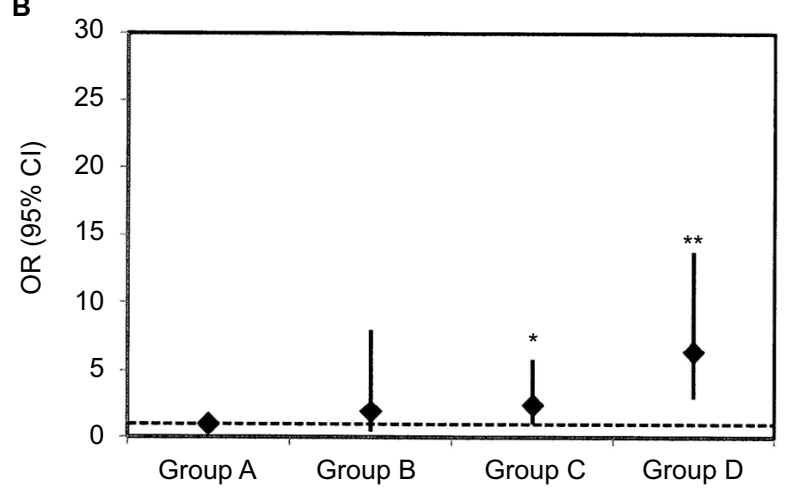

D

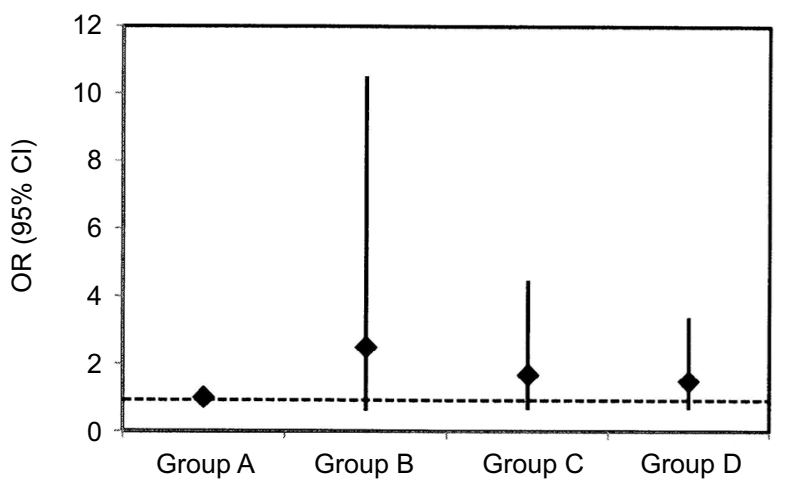

$\mathbf{F}$

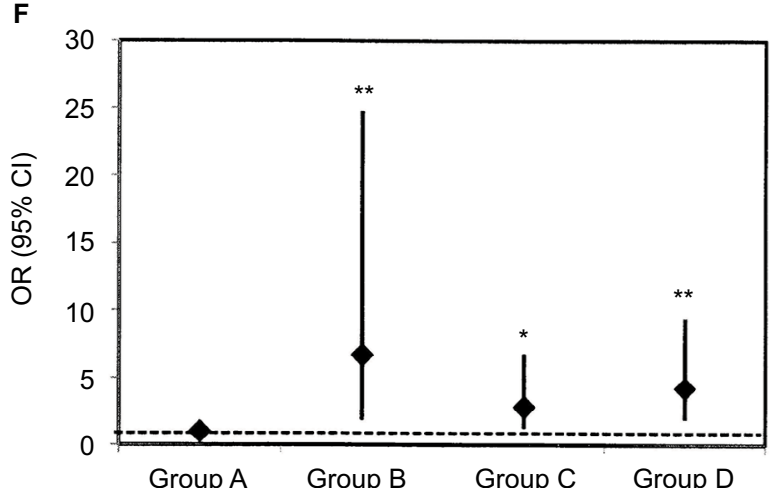

H

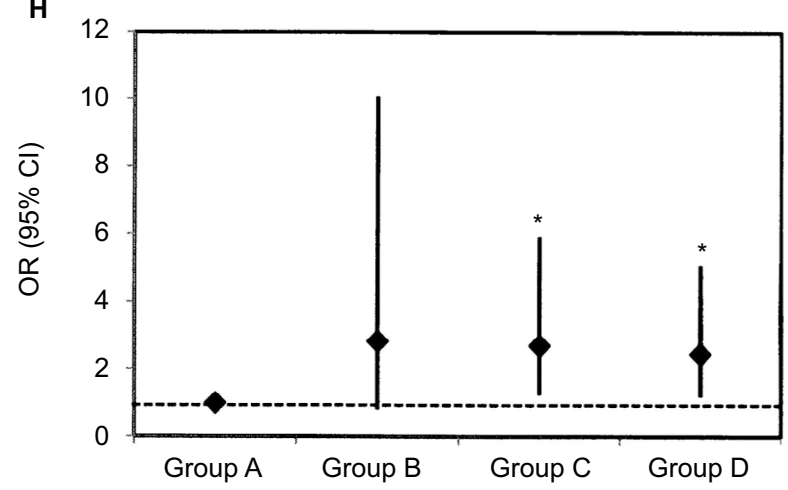

Figure 2 Multinomial logistic regression analysis for $(\mathbf{A})$ hypertension, $(\mathbf{B})$ insulin resistance, $(\mathbf{C})$ impaired fasting glucose, (D) increased HbAlc, (E) hypertriglyceridemia, (F) hypo HDL cholesterolemia, $(\mathbf{G})$ atherogenic lipoproteins, and $(\mathbf{H})$ atherogenic lipoprotein pattern for the following groups compared with the reference normal-weight and lean group (Group A): overweight and lean (Group B), BMI $\geq 25.0 \mathrm{~kg} / \mathrm{m}^{2}$ for women and $\geq 27.0 \mathrm{~kg} / \mathrm{m}^{2}$ for men, and PBF $<35 \%$ for women and $<25 \%$ for men; normal weight and fat (Group C), body mass index (BMI) $<25.0 \mathrm{~kg} / \mathrm{m}^{2}$ for women and $<27.0 \mathrm{~kg} / \mathrm{m}^{2}$ for men, and percentage of body fat (PBF) $\geq 35 \%$ for women and $\geq 25 \%$ for men; and overweight and fat (Group D), BMI $\geq 25.0 \mathrm{~kg} / \mathrm{m}^{2}$ for women and $\geq 27.0 \mathrm{~kg} / \mathrm{m}^{2}$ for men, and PBF $\geq 35 \%$ for women and $\geq 25 \%$ for men. Note: $* P<0.05 ; * * P<0.01$. 
Table 4 Logistic regression analysis of obesity measures associated with CVD risk factors

\begin{tabular}{|c|c|c|c|c|c|}
\hline \multirow[t]{2}{*}{ Dependent variables } & \multirow{2}{*}{$\begin{array}{l}\text { Independent } \\
\text { variables }\end{array}$} & \multicolumn{2}{|l|}{ Men } & \multirow{2}{*}{$\frac{\text { Women }}{\text { OR }(95 \% \mathrm{CI})^{\mathrm{a}}}$} & \multirow[b]{2}{*}{$P$-value } \\
\hline & & OR $(95 \% \mathrm{Cl})^{\mathrm{a}}$ & $P$-value & & \\
\hline \multirow[t]{2}{*}{ Blood pressure $^{b}$} & BMI & 7.65 (2.23-26.32) & 0.001 & $3.56(1.53-8.27)$ & 0.003 \\
\hline & PBF & - & - & - & - \\
\hline \multirow[t]{2}{*}{ HOMA-IRc } & BMI & - & - & $3.23(1.45-7.00)$ & 0.003 \\
\hline & PBF & $9.37(2.90-30.29)$ & $<0.001$ & - & - \\
\hline \multirow[t]{2}{*}{ Fasting glucose ${ }^{d}$} & BMI & - & - & $2.40(1.07-5.38)$ & 0.033 \\
\hline & PBF & 4.25 (1.54-II.78) & 0.005 & - & - \\
\hline \multirow[t]{2}{*}{$\mathrm{HbAlc} \mathrm{c}^{\mathrm{e}}$} & BMI & - & - & - & - \\
\hline & PBF & - & - & - & - \\
\hline \multirow[t]{2}{*}{ Triglycerides ${ }^{f}$} & BMI & - & - & $2.74(1.19-6.32)$ & 0.018 \\
\hline & PBF & $5.38(1.93-15.00)$ & $<0.001$ & - & - \\
\hline \multirow{2}{*}{ HDL-Cg } & BMI & $6.69(1.61-27.8)$ & 0.009 & $2.91(1.35-6.26)$ & 0.006 \\
\hline & PBF & - & - & - & - \\
\hline \multirow[t]{2}{*}{ Small-dense LDL ${ }^{\mathrm{h}}$} & BMI & - & - & - & - \\
\hline & PBF & $3.27(1.20-8.87)$ & 0.020 & $2.31(1.20-4.47)$ & 0.013 \\
\hline \multirow[t]{2}{*}{ LDL particle size $^{i}$} & BMI & - & - & - & - \\
\hline & PBF & $3.48(1.27-9.58)$ & 0.016 & $2.16(1.06-4.39)$ & 0.033 \\
\hline \multirow[t]{2}{*}{ hsCRPi } & BMI & - & - & - & - \\
\hline & PBF & - & - & - & - \\
\hline \multirow[t]{2}{*}{ 25-hydroxyvitamin $D^{k}$} & BMI & - & - & - & - \\
\hline & PBF & - & - & - & - \\
\hline \multirow[t]{2}{*}{ Leptin' } & BMI & - & - & $27.5(3.37-224.6)$ & 0.002 \\
\hline & PBF & $15.09(1.50-152.1)$ & 0.021 & - & - \\
\hline \multirow[t]{2}{*}{ Adiponectin $^{m}$} & BMI & - & - & $2.51(1.21-5.23)$ & 0.014 \\
\hline & PBF & - & - & - & - \\
\hline
\end{tabular}

Notes: aData are from logistic regression analyses adjusted for age, height, and smoking; Dashes mean variable removed from the equation by backward stepwise selection. ${ }^{b}$ Defined as systolic $\geq 130$ and/or diastolic $\geq 85 \mathrm{mmHg}$ or treatment with antihypertensive drug. 'Defined as HOMA-IR $\geq 3.0$. ${ }^{\mathrm{d}} \mathrm{Defined}$ as glucose $\geq 5.55 \mathrm{mmol} / \mathrm{L}$ or previous diagnosis of diabetes. ${ }^{e}$ Defined as HbAlc $\geq 38.8 \mathrm{mmol} / \mathrm{mol}$. ${ }^{\mathrm{f} D e f i n e d ~ a s ~ t r i g l y c e r i d e s ~} \geq 1.70 \mathrm{mmol} / \mathrm{L}$. ${ }^{8}$ Defined as HDL-C $<1.04 \mathrm{mmol} / \mathrm{L}$ (men) or $<1.30 \mathrm{mmol} / \mathrm{L}$ (women). ${ }^{h}$ Defined as small-dense LDL $>0.16 \mathrm{mmol} / \mathrm{L}$. 'Defined as mean LDL particle size $<26.5 \mathrm{~nm}$. 'Defined as hsCRP $>3.0 \mathrm{mg} / \mathrm{L}$. kDefined as $25-\mathrm{hydroxyvitamin} \mathrm{D}<50 \mathrm{nmol} / \mathrm{L}$. 'Defined as leptin over upper limit: $>12.0 \mathrm{ng} / \mathrm{mL}$ (men) or $>24.2 \mathrm{ng} / \mathrm{mL}$ (women). ${ }^{\mathrm{m}}$ Defined as adiponectin lower upper limit: $<13.9 \mu \mathrm{g} / \mathrm{mL}$ (men) or $<19.4 \mu \mathrm{g} / \mathrm{mL}$ (women).

Abbreviations: BMI, body mass index; Cl, confidence interval; CVD, cardiovascular disease; HbAlc, hemoglobin Al c; HOMA-IR, Homeostasis Model Assessment of Insulin Resistance; HDL-C, high density lipoprotein-cholesterol; hsCRP, high sensitive C-reactive protein; LDL, low density lipoprotein; OR, odds ratio; PBF, percentage of body fat.

leptin was associated with PBF for men and BMI for women, whereas adiponectin had no association in any way for men, but agreed with BMI for women.

\section{Discussion}

BMI and PBF are two different clinical measures of obesity. However, whether the two measures are equally applicable in certain populations is unclear. For example, Asian populations tend to have a higher PBF and related complications compared with other ethnic populations with the same BMI. ${ }^{16}$ Moreover, many results have indicated sex-related differences in regulation of adipose tissue; women have a greater amount of PBF than men with an equivalent BMI. ${ }^{17,21}$ The question is whether the use of only one measure or the other is sufficient. Our results reveal that neither measure used alone is sufficient.

For the Thai population, our results show a good relationship between BMI and PBF when sex stratification was accounted for. According to our data, the proportions of men were similar in all groups when using either BMI or PBF for classification (Tables 1 and 2). This implies that sex-specific cutoff points regarding BMI and PBF are appropriate for defining excess body weight and body fat for the adult Thai population. According to such criteria, 27.8\% of the participants were identified to be obese using the sex-specific BMI cutoff, but $40.6 \%$ were determined to be fat using the PBF cutoff. Our results are similar to those of the recently published study of Gába and Přidalová, who demonstrated that although $21 \%$ of Caucasian women studied had a BMI of $\geq 30 \mathrm{~kg} / \mathrm{m}^{2}, 40 \%$ had a high excess fat mass. ${ }^{22}$ Notably, among our normal-weight participants, $25 \%$ were found to have PBF that was higher than the cutoff value. Indeed, in Group $C$ and $\mathrm{D}$, there was a marked increase in the waist-to-hip fat ratio and the visceral fat area compared with Group A and B. Such results indicate the poor diagnostic performance of BMI in measuring increased body fat (adiposity) in this population.

In the present study, we observed that BMI and PBF differed considerably in their predictive abilities for numerous 
cardiometabolic risk markers (Figure 2). Furthermore, we observed large differences in the abilities of the BMI and PBF measures to identify specific risk factors, as shown by the ORs (Table 4). A good discriminator for individual participants being at risk of hypertension was being overweight (with or without fat). Moreover, BMI, and not PBF, was strongly associated with hypertension, independent of age, height, or sex. A study of Chinese adults by Hou et al found that BMI adequately reflected body volume and mass, and this was associated with blood viscosity and blood volume and was closely related to blood pressure. ${ }^{23}$ However, in our Thai population, the magnitude of the association between BMI and hypertension was much higher in men (an OR that was twice as large in men than in women).

According to results of glucose and lipid metabolic profiles, individual participants who were overweight and fat clearly demonstrated a high risk of all metabolic regulations, except for increased $\mathrm{HbA} 1 \mathrm{c}$. Additionally, our data indicate that participants with a contradictory BMI and PBF (normal weight and fat or overweight and lean) may be misidentified as being at risk of glucose and lipid metabolic dysregulations. Furthermore, participants identified as being of a normal weight but fat also demonstrated a risk of insulin resistance. This result supports the report by Romero-Corral et al that individuals with a high body fat content but a normal weight were more predisposed to type II diabetes mellitus than those who were overweight but had a normal fat mass. ${ }^{24}$ Notably, however, our results indicate that participants who were either normal weight and fat or overweight and/or fat did not appear to be at risk of increasing levels of HbA1c. This finding is in agreement with that of Mainous et al, who reported that BMI and waist circumference showed no association with HbA1c. ${ }^{25} \mathrm{HbA} 1 \mathrm{c}$ reflects an increase in average glucose levels. However, participants in Group D were overweight and fat (Table 3), but they showed no marked glucose increase compared with Group A (107.1 vs $94.5 \mathrm{mg} / \mathrm{dL}$, only a $14 \%$ increase), which may not be sufficient to significantly increase hemoglobin glycosylation. Insulin resistance differed between the participants with overweight and fat and normal weight and lean (2.087 vs 0.850, a 145\% increase). An increase in insulin secretion ( 7.37 vs $3.52 \mu \mathrm{IU} / \mathrm{mL}$, a $108 \%$ increase) may have restrained the glucose concentration. Another population-based study showed that the agreement between HbA1c and oral glucose tolerance test criteria in classifying participants' glycemia decreased with an increase in the participants' BMI, particularly when screening for prediabetes (HbA1c ranged from $5.7 \%$ to $6.4 \%$ ). ${ }^{26}$
We noted a large sex-specific variation between BMI and PBF with respect to their association with the serum metabolite profile. Multiple studies have shown that individuals with a large body fat content are predisposed not only to type II diabetes mellitus but also to CVD. ${ }^{4-7}$ We observed that HOMA-IR, fasting glucose, and triglycerides were similarly associated with PBF in men but not in women. By contrast, BMI was shown to be a good predictor of these risk factors in women. Women tend to have more body fat than men. Furthermore, because of distinct differences in fatty acid mobilization and oxidation and storage, women tend to store more fat in the gluteal-femoral region, whereas men store more fat in the visceral depot. ${ }^{27}$ Therefore, the use of BMI as an indicator of CVD and type II diabetes mellitus for women is preferable over the use of PBF in evaluating changes in body adiposity over time, because changes in body weight are more likely to represent an increase in the volume of adipose tissue.

The lipid metabolic profiles showed differences between BMI and PBF in their ability to predict each of the lipid risk factors. Although numerous studies have reported a direct correlation between increasing adiposity and dyslipidemia, our results reveal no significant differences in total cholesterol, LDL-C, IDL-C, or non-HDL-C between the normalweight and overweight or lean and fat groups. ${ }^{28,29}$ However, notably, PBF in both sexes was a predictor for only increased small-dense LDL particle size and decreased LDL particle size, which play an important role in the development of atherosclerosis. These data are consistent with the data of Rainwater et al, who showed that changes in metabolic conditions (such as obesity) predominantly affect LDL particle size more than LDL absolute levels. ${ }^{30}$ Notably, many studies have demonstrated that small-dense LDL particles were strongly associated with raised triglycerides and decreased HDL-C concentrations, whereas we found differences between the obesity measures in their ability to predict these lipids abnormalities. ${ }^{31,32} \mathrm{BMI}$ was strongly associated with low HDL-C in both sexes, whereas PBF was strongly associated with small-dense LDL particles. In addition, we observed a trend where participants who were overweight exhibited a greater probability of having low HDL-C compared with those who were considered fat (Figure 2F). According to Pietrobelli et al, the composition of HDL may be altered through muscle lipoprotein lipase-mediated transfer of cholesterol esters from HDL to triglycerides-rich lipoprotein remnants, which leads to increased HDL catabolism. ${ }^{33}$ Furthermore, a recent cohort 
study in women with a high prevalence of MetS showed that trunk fat-free soft tissue mass may have detrimental effects on HDL levels. ${ }^{34}$ Data from the current study also demonstrate that participants classified as being obese according to BMI but having normal fat mass according to PBF tended to have a high muscle mass, and they showed the lowest HDL-C and apoA-I levels (Table 3). Therefore, not only adipose tissue but also nonadipose components, particularly muscle mass, may play an important role in HDL metabolism.

Notably, the predictive abilities of both BMI and PBF were quite similar with respect to HOMA-IR and to glucose and triglyceride concentrations; BMI was a better predictor for women and PBF for men. Remarkably, these patterns were also observed for leptin levels. This indicates that muscle and adipose tissues influence the regulation of several important physiological functions and that there is a close link between adipokine and glucose and lipid metabolisms.

Hypertension, insulin resistance, hyperglycemia, dyslipidemia, increase inflammatory markers, and 25-hydroxyvitamin $\mathrm{D}$ deficiency have been studied with respect to an associated CVD risk. ${ }^{35,36}$ However, our results reveal no association between BMI or PBF and hsCRP or 25-hydroxyvitamin D. Although low 25-hydroxyvitamin D levels have been extensively reported in obesity, we notably found that 25-hydroxyvitamin D levels were similar between normal and obese participants, independent of the obesity measure used. ${ }^{37}$ Inconsistencies in the reporting of associations between serum 25-hydroxyvitamin $\mathrm{D}$ and obesity may be due to the high levels of vitamin $\mathrm{D}$ inadequacy in the Thai population, which were up to $44.3 \%$ and $91.9 \%$, as defined by 25 -hydroxyvitamin D levels less than 50 and $75 \mathrm{nmol} / \mathrm{L}$, respectively. ${ }^{38}$

Our study has some limitations. First, only a few participants were defined as having an excess BMI with a normal PBF, which may limit our conclusions. Therefore, further studies involving larger and different Southeast Asian populations are required to confirm the findings presented herein. Second, age, sex, height, and smoking status are known to be risk factors associated with developing CVD risk factors; although these factors were accounted for and adjusted in our analysis, other factors were not accounted for, despite being known to be risk factors in developing CVD (such as dietary intake, level of education, physical activity, and family history). Third, we measured PBF in this study by using bioelectrical impedance analysis, which tends to underestimate body fat in subjects. ${ }^{39}$ However, this method of analysis is used in large-scale epidemiological investigations because it is least expensive and is the most simple and reproducible method used to conduct PBF evaluations and other body composition assessments. ${ }^{40}$

\section{Conclusion}

This study was conducted on a Thai population, and the results reveal that Thai women have a higher PBF than men. In particular, the two measures of obesity (BMI and PBF) exhibited considerable sex-specific variations in terms of their associations with cardiometabolic risk profiles. With respect to glucose homeostasis and to triglyceride and leptin concentrations, BMI was a better predictor for women and PBF for men. In addition, we clearly demonstrated that participants with a contradictory BMI and PBF could be misidentified as being at risk of glucose and lipid metabolic dysregulations. The differences between the two measures in terms of their prediction of cardiometabolic risk indicate that using exclusively one or the other measure provides an inferior risk prediction than using both measures, as shown herein with the Thai population. Therefore, because both BMI and PBF are easy and inexpensive to use, both should be applied in screening activities.

\section{Availability of data and material}

The datasets used and/or analyzed during the current study will not be shared. For access to this data, please contact Pornpen Srisawasdi, $\mathrm{PhD}$, the supervisor of the study, at pornpen.sri@mahidol.ac.th or srisawasdiP@yahoo.com

\section{Acknowledgments}

The authors gratefully acknowledge all participants who contributed to this study. The authors would like to thank Boontarika Intachak, Jirapa Kerdmongkol and all staff in Division of Clinical Chemistry, Department of Pathology, Faculty of Medicine, Ramathibodi Hospital, Mahidol University, Thailand for data collection and management. This study was supported by a Research Grant from the Faculty of Medicine, Ramathibodi Hospital, Mahidol University, Thailand (grant number 56076).

\section{Author contributions}

All the authors participated in the interpretation and the review of the manuscript. PS, SV, and MR designed the study. PS, SV, NK, and KK conducted the data retrieval and analyzed the data. PS, SV, and MHK wrote the manuscript. PS, SV, MR, and MHK gave constructive suggestions during 
the preparation of the manuscript. All the authors read and approved the final manuscript. All the authors also participated in revision of the manuscript.

\section{Disclosure}

The authors report no conflicts of interest in this work.

\section{References}

1. World Health Organization. Obesity and overweight. Fact sheet No. 311, Updated October 2017. Available from: http://www.who.int/ mediacentre/factsheets/fs311/en. Accessed May 10, 2018.

2. NCD Risk Factor Collaboration (NCD-RisC). Trends in adult body-mass index in 200 countries from 1975 to 2014: a pooled analysis of 1698 population-based measurement studies with $19 \cdot 2$ million participants. Lancet. 2016;387(10026):1377-1396.

3. Park HK, Ahima RS. Physiology of leptin: energy homeostasis, neuroendocrine function and metabolism. Metabolism. 2015;64(1):24-34.

4. Cornier MA, Després JP, Davis N, et al; American Heart Association Obesity Committee of the Council on Nutrition; Physical Activity and Metabolism; Council on Arteriosclerosis; Thrombosis and Vascular Biology; Council on Cardiovascular Disease in the Young; Council on Cardiovascular Radiology and Intervention; Council on Cardiovascular Nursing, Council on Epidemiology and Prevention; Council on the Kidney in Cardiovascular Disease, and Stroke Council. Assessing adiposity: a scientific statement from the American Heart Association. Circulation. 2011;124(18):1996-2019.

5. Stefan N, Fritsche A, Schick F, Häring HU. Phenotypes of prediabetes and stratification of cardiometabolic risk. Lancet Diabetes Endocrinol. 2016;4(9):789-798.

6. Flegal KM, Kit BK, Orpana H, Graubard BI. Association of all-cause mortality with overweight and obesity using standard body mass index categories: a systematic review and meta-analysis. JAMA. 2013;309(1): $71-82$.

7. Winter JE, MacInnis RJ, Wattanapenpaiboon N, Nowson CA. BMI and all-cause mortality in older adults: a meta-analysis. Am J Clin Nutr. 2014;99(4):875-890.

8. Jackson AS, Stanforth PR, Gagnon J, et al. The effect of sex, age and race on estimating percentage body fat from body mass index: the Heritage Family Study. Int J Obes Relat Metab Disord. 2002;26(6): 789-796.

9. Lichtash CT, Cui J, Guo X, et al. Body adiposity index versus body mass index and other anthropometric traits as correlates of cardiometabolic risk factors. PLoS One. 2013;8(6):e65954.

10. Heo M, Faith MS, Pietrobelli A, Heymsfield SB. Percentage of body fat cutoffs by sex, age, and race-ethnicity in the US adult population from NHANES 1999-2004. Am J Clin Nutr. 2012;95(3):594-602.

11. Wong WW, Strizich G, Heo M, et al. Relationship between body fat and BMI in a US hispanic population-based cohort study: results from HCHS/SOL. Obesity (Silver Spring). 2016;24(7):1561-1571.

12. Deurenberg P, Yap M, van Staveren WA. Body mass index and percent body fat: a meta analysis among different ethnic groups. Int $J$ Obes Relat Metab Disord. 1998;22(12):1164-1171.

13. World Health Organization. Physical status: the use and interpretation of anthropometry. Report of a WHO Expert Committee. WHO Technical Report Series 854. Available from: http://apps.who.int/iris/ bitstream/10665/37003/1/WHO_TRS_854.pdf. Accessed May 10, 2018.

14. Okorodudu DO, Jumean MF, Montori VM, et al. Diagnostic performance of body mass index to identify obesity as defined by body adiposity: a systematic review and meta-analysis. Int $J$ Obes (Lond). 2010;34(5):791-799.

15. WHO Expert Consultation. Appropriate body-mass index for Asian populations and its implications for policy and intervention strategies. Lancet. 2004;363(9403):157-163.
16. Wang J, Thornton JC, Russell M, Burastero S, Heymsfield S, Pierson RN Jr. Asians have lower body mass index (BMI) but higher percent body fat than do whites: comparisons of anthropometric measurements. Am J Clin Nutr. 1994;60(1):23-28.

17. Carpenter CL, Yan E, Chen S, et al. Body fat and body-mass index among a multiethnic sample of college-age men and women. $J$ Obes. 2013;2013:790654

18. Pongchaiyakul C, Nguyen TV, Kosulwat V, et al. Defining obesity by body mass index in the Thai population: an epidemiologic study. Asia Pac J Clin Nutr. 2006;15(3):293-299.

19. Romero-Corral A, Montori VM, Somers VK, et al. Association of bodyweight with total mortality and with cardiovascular events in coronary artery disease: a systematic review of cohort studies. Lancet. 2006;368(9536):666-678.

20. Alberti KG, Eckel RH, Grundy SM, et al; International Diabetes Federation Task Force on Epidemiology and Prevention; National Heart, Lung, and Blood Institute; American Heart Association; World Heart Federation; International Atherosclerosis Society; International Association for the Study of Obesity. Harmonizing the metabolic syndrome: a joint interim statement of the International Diabetes Federation Task Force on Epidemiology and Prevention; National Heart, Lung, and Blood Institute; American Heart Association; World Heart Federation; International Atherosclerosis Society; and International Association for the Study of Obesity. Circulation. 2009;120(16):1640-1645.

21. Palmer BF, Clegg DJ. The sexual dimorphism of obesity. Mol Cell Endocrinol. 2015;402:113-119.

22. Gába A, Přidalová M. Diagnostic performance of body mass index to identify adiposity in women. Eur J Clin Nutr. 2016;70(8): 898-903.

23. Hou X, Lu J, Weng J, et al; China National Diabetes and Metabolic Disorders Study Group. Impact of waist circumference and body mass index on risk of cardiometabolic disorder and cardiovascular disease in Chinese adults: a national diabetes and metabolic disorders survey. PLoS One. 2013;8(3):e57319.

24. Romero-Corral A, Somers VK, Sierra-Johnson J, et al. Normal weight obesity: a risk factor for cardiometabolic dysregulation and cardiovascular mortality. Eur Heart J. 2010;31(6):737-746.

25. Mainous AG 3rd, Tanner RJ, Coates TD, Baker R. Prediabetes, elevated iron and all-cause mortality: a cohort study. BMJ Open. 2014;4(12):e006491.

26. Li J, Ma H, Na L, et al. Increased hemoglobin A1c threshold for prediabetes remarkably improving the agreement between A1c and oral glucose tolerance test criteria in obese population. $J$ Clin Endocrinol Metab. 2015;100(5):1997-2005.

27. Blaak E. Gender differences in fat metabolism. Curr Opin Clin Nutr Metab Care. 2001;4(6):499-502.

28. Shamai L, Lurix E, Shen M, et al. Association of body mass index and lipid profiles: evaluation of a broad spectrum of body mass index patients including the morbidly obese. Obes Surg. 2011;21(1): $42-47$.

29. Klop B, Elte JW, Cabezas MC. Dyslipidemia in obesity: mechanisms and potential targets. Nutrients. 2013;5(4):1218-1240.

30. Rainwater DL, Mitchell BD, Comuzzie AG, Haffner SM. Relationship of low-density lipoprotein particle size and measures of adiposity. Int J Obes Relat Metab Disord. 1999;23(2):180-189.

31. Tsimihodimos V, Gazi I, Kostara C, Tselepis AD, Elisaf M. Plasma lipoproteins and triacylglycerol are predictors of small, dense LDL particles. Lipids. 2007;42(5):403-409.

32. Kathiresan S, Otvos JD, Sullivan LM, et al. Increased small low-density lipoprotein particle number: a prominent feature of the metabolic syndrome in the Framingham Heart Study. Circulation. 2006;113(1): $20-29$.

33. Pietrobelli A, Lee RC, Capristo E, Deckelbaum RJ, Heymsfield SB. An independent, inverse association of high-density-lipoproteincholesterol concentration with nonadipose body mass. Am J Clin Nutr. 1999;69(4):614-620. 
34. Jean-Luc Gradidge P, Norris SA, Jaff NG, Crowther NJ. Metabolic and body composition risk factors associated with metabolic syndrome in a cohort of women with a high prevalence of cardiometabolic disease. PLoS One. 2016;11(9):e0162247.

35. Ridker PM. Clinical application of C-reactive protein for cardiovascular disease detection and prevention. Circulation. 2003;107(3): 363-369.

36. Judd S, Tangpricha V. Vitamin D Deficiency and Risk for Cardiovascular Disease. Circulation. 2008;117(4):503-511.

37. Pereira-Santos M, Costa PR, Assis AM, Santos CA, Santos DB. Obesity and vitamin D deficiency: a systematic review and meta-analysis. Obes Rev. 2015;16(4):341-349.
38. Nimitphong H, Chanprasertyothin S, Jongjaroenprasert W, Ongphiphadhanakul $\mathrm{B}$. The association between vitamin $\mathrm{D}$ status and circulating adiponectin independent of adiposity in subjects with abnormal glucose tolerance. Endocrine. 2009;36(2):205-210.

39. Sun G, French CR, Martin GR, et al. Comparison of multifrequency bioelectrical impedance analysis with dual-energy X-ray absorptiometry for assessment of percentage body fat in a large, healthy population. Am J Clin Nutr. 2005;81(1):74-78.

40. Ling CH, de Craen AJ, Slagboom PE, et al. Accuracy of direct segmental multi-frequency bioimpedance analysis in the assessment of total body and segmental body composition in middle-aged adult population. Clin Nutr. 2011;30(5):610-615.
Diabetes, Metabolic Syndrome and Obesity: Targets and Therapy is an international, peer-reviewed open-access journal committed to the rapid publication of the latest laboratory and clinical findings in the fields of diabetes, metabolic syndrome and obesity research. Original research, review, case reports, hypothesis formation, expert opinion and commentaries are all considered for publication. The manuscript management system is completely online and includes a very quick and fair peer-review system, which is all easy to use. Visit http://www.dovepress.com/testimonials.php to read real quotes from published authors.

Submit your manuscript here: https://www.dovepress.com/diabetes-metabolic-syndrome-and-obesity-targets-and-therapy-journal 